\title{
CARDIOMYOPATHY IN FOUR MEMBERS OF A FAMILY
}

\author{
BY \\ J. M. BISHOP, MAURICE CAMPBELL, AND E. WYN JONES \\ From Queen Elizabeth Hospital, Birmingham, Guy's Hospital, and the Liverpool Royal Infirmary \\ Received June 12, 1962
}

We are describing briefly another family with cardiomyopathy, where a woman and three of her four children were affected. Some of them have been under observation for twelve years and have been examined by the three authors at different periods. The mother had been suspected for many years of having some form of congenital heart disease because of a murmur. She and her three affected children were seen in 1948-51 at Liverpool by E.W.J.: he was impressed by the triple rhythm and by the mitral shape of the heart but did not think they had mitral stenosis. Later in 1950 one of the boys, then aged 15, died while playing football though he had been advised not to play. His mother died in 1952, at the age of 47 with cardiomyopathy, a large heart, atrial fibrillation, and intracardiac thrombosis.

In 1956, the two survivors, the sister and the youngest brother were seen by M.C. at Guy's Hospital. They were admitted for catheterization but permission for this was withdrawn so there was only a clinical examination. Triple rhythm was still one of the most striking features, and the diagnosis was thought to be familial cardiomyopathy.

The youngest brother died suddenly when walking in the street at the age of 17 in 1960 . This death and the occurrence of congestive heart failure in the sister after a successful pregnancy led to her admission under J.M.B. at Birmingham for cardiac catheterization. This revealed no congenital structural malformation but some left ventricular insufficiency on exercise and so supported the diagnosis of cardiomyopathy. She was given quinidine to try to prevent the occurrence of serious arrhythmias, and has remained reasonably well for 20 months but her outlook must be uncertain.

A son of the mother's brother, a first cousin of the three sibs, died suddenly from heart disease when he was 42 but he had complained of anginal pain for four years so he may not have had a cardiomyopathy. The other members of the family appear to be free from heart disease.

\section{Notes ABOUT Members OF THE FAMILY}

First Generation. The grandparents of our three children were first cousins; they had no knowledge of any earlier family history of heart disease. They were both in good health in 1956, but have since died, aged 91 and 88 years. They had eight children.

Second Generation. Six of their eight children (4 brothers and 2 sisters) are well and without any suggestion of a cardiomyopathy: their ages now range between 58 and 72 years. One sister died at the age of 14 from meningitis. The eighth is our Case 1 (Fig. 1).

The husband of Case 1 does not appear to be the source of the cardiomyopathy in his children. $\mathrm{He}$ is alive and well though in the past he has been treated for pulmonary tuberculosis: his heart appears to be normal and has a normal size and outline on X-ray examination. He has no knowledge of any earlier relatives with heart disease.

Case 1. Mrs. T. died in 1952 when she was 47. She had a systolic murmur that had been thought to indicate congenital heart disease, but had no special symptoms with her four pregnancies and led a normal and active life as a housewife till she was 45 . She then became increasingly dyspnœic and saw one of us 


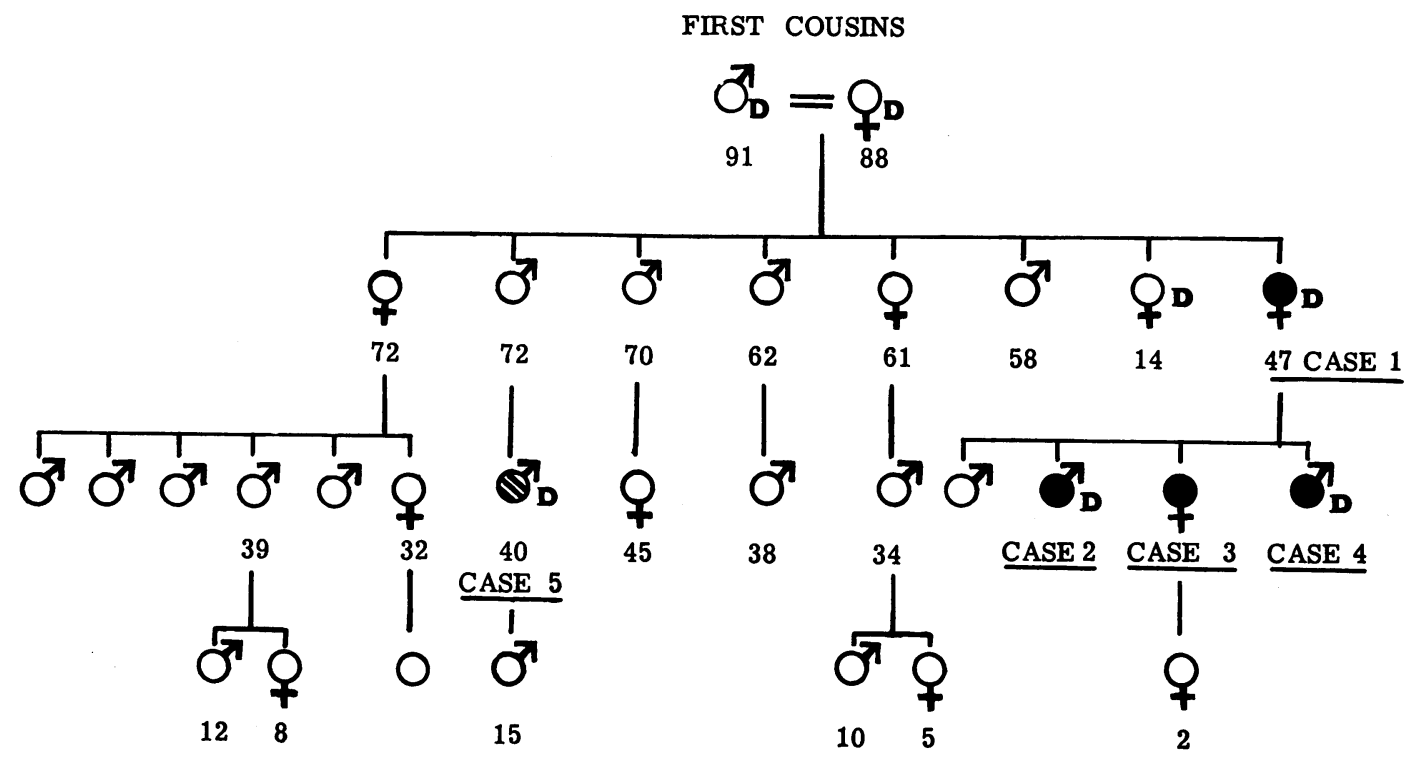

Fig. 1.-Family tree of our patients, showing a family where relatively few members were affected.

of indicate subjects with cardiomyopathy

$\sigma^{*}+$ indicate subjects without evidence of cardiomyopathy indicates possible cardiomyopathy in one man: he had two sibs who died in infancy but their sex is not known.

Where the subject is marked $D$, the figure below is the age at death: otherwise it is the age of the subject at present.

(E.W.J.) in September 1950. He found no signs of congestive failure, a normal blood pressure, 120/80, a large heart, especially the left ventricle, a basal systolic murmur, and a triple rhythm at the apex that was difficult to time. Her cardiogram showed a prolonged P-R interval and left ventricular preponderance.

She was X-rayed several times in the next ten months. The heart was enlarged generally but mainly the left atrium and left ventricle; the apex was rounded and the left border slightly convex. In June 1951 the lung hila were congested, there was some effusion at both bases, and the heart shape was suggestive of mitral stenosis. Both the radiologist and E.W.J. commented on the similarities they observed between the heart of the mother and her two children that they had seen.

By June 1951, she had developed congestive failure. The rhythm was irregular, due to atrial flutter (A, 350; V, 84) and though it was restored to normal with quinidine this did not last and subsequent records showed sometimes flutter and sometimes fibrillation. Nearly two years after the onset of heart failure she had embolic arterial occlusion of the left leg and two weeks later (June 1952, aged 47) she died with a pulmonary embolism that came from the wall of the right ventricle.

Necropsy. The heart was large and weighed $510 \mathrm{~g}$. The lungs were congested with a few small recent infarcts; there was a large pulmonary embolus which had come from a thrombus in the region of the tricuspid valve, which was firmly adherent to the right ventricular wall at its origin. There were also large adherent thrombi in the left atrium. This and the left ventricle were both grossly enlarged and showed numerous sub-pericardial petechiæ. The valves were all normal, as were the coronary arteries.

In the abdominal aorta there was a firm adherent thrombus from the level of the cœliac axis down to the femoral arteries and this was in the process of recanalizing at one point. There were several old infarcts in both kidneys and a large recent one in the left. The other viscera were normal except for congestion. The liver was enlarged and weighed $1590 \mathrm{~g}$. Intracardiac thrombosis is uncommon in a case of lone atrial fibrillation having regular treatment but she had no evidence of disease of the valves.

On section (Dr. T. J. A. Lloyd) the myocardium showed widespread replacement of muscle by fibrous tissue. The endocardium was thickened by similar fibrosis, in some areas with overlying thrombus. Many of the arteries supplying the heart muscle were narrowed by intimal hyperplasia. The aorta showed patchy intimal thickening and fibrous replacement of smooth muscle. The lungs and liver showed congestive changes only, and the kidneys showed areas of infarction. Dr. L. Wise, Pathologist to the Wrexham Hospitals, kindly sent us these blocks and they have been cut again and examined for us by Dr. Missen who found organizing mural thrombi, fibro-elastic endocardial thickening, patchy myocardial fibrosis, and mucoid degeneration (Spencer, 1950) of some myocardial fibres (Fig. 2 and 3). 


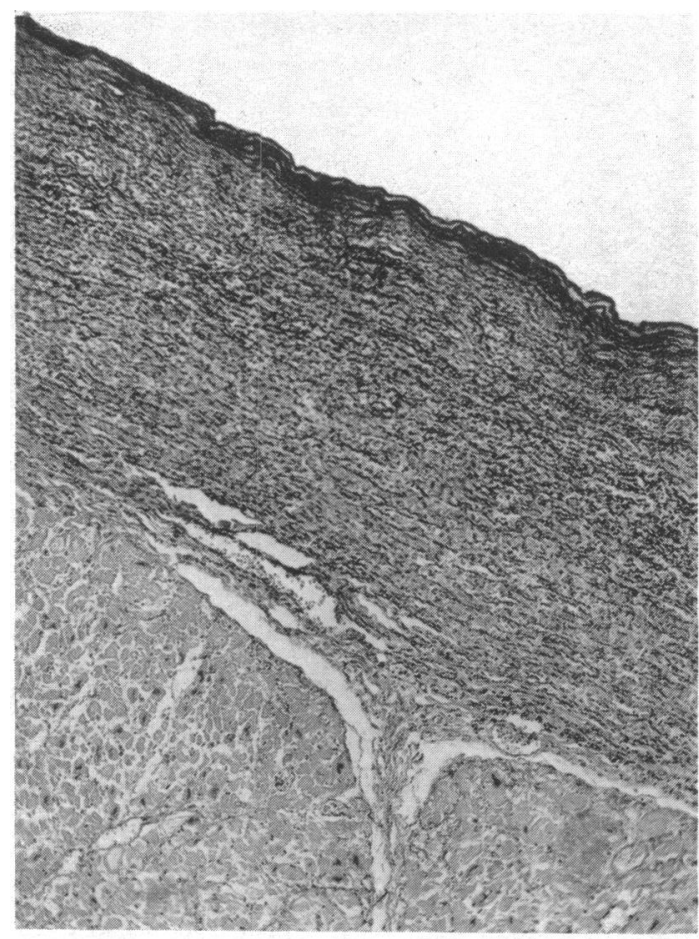

A

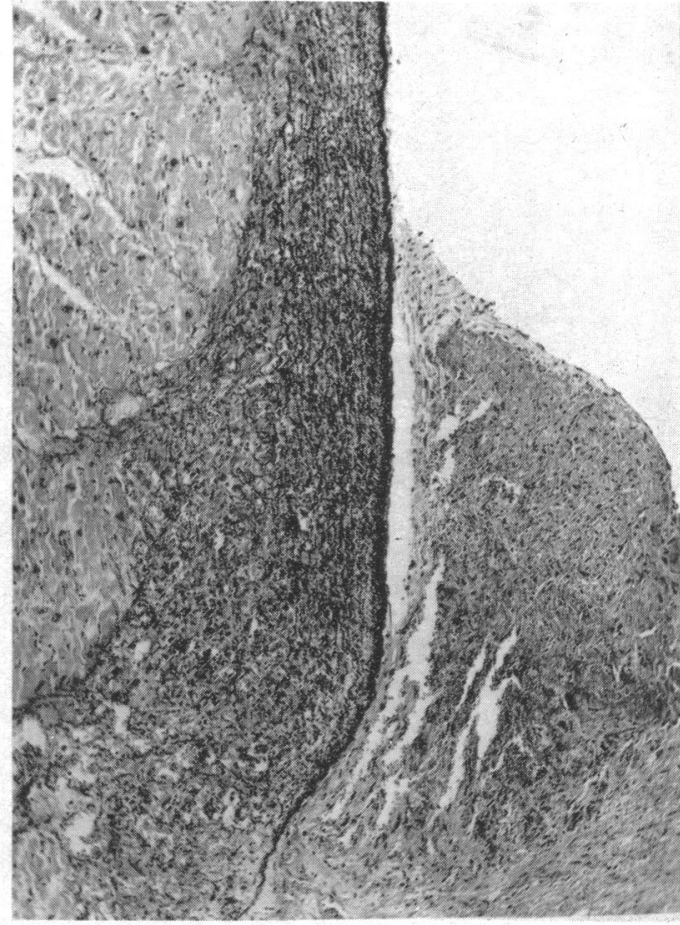

B

FIG. 2.-(A) Heart showing severe fibro-elastic endocardial thickening. $\times 90$. (B) Heart showing fibroelastic endocardial thickening and organizing mural thrombus. $\times 74$. Both stained with Weigert's elastic stain, hæmatoxylin, and van Gieson.

The Third Generation. There were four children of Case 1: her eldest son, aged 30 in 1960, is thought to have a normal heart; and the other three are our Cases 2, 3, and 4.

There were 12 children of the sibs of Case 1. Two died in infancy of unknown causes. Case 5 died at the age of 42 but this was more likely from coronary heart disease than from cardiomyopathy. The other 9 are alive and well, at ages ranging from 32 to 45 years, and no evidence of cardiomyopathy has been found.

Case 2. The second son of Case 1 died suddenly playing football when he was 16 (1950). One of us (E.W.J.) had seen him in 1948 and obtained the following history. He had always been short of breath but was able to play football. When playing a few days before he had felt faint with some discomfort in the chest but after a rest had finished the game. He had a curious triple rhythm at the apex (? duplication of the first sound). The blood pressure was $110 / 70 \mathrm{~mm}$. There was nothing striking in the cardiogram except large notched $\mathbf{P}$ waves in lead I. On radioscopy there was generalized cardiac enlargement with a " $\mathrm{mitral}$ shape," but no diastolic murmur was heard and he was not thought to have mitral stenosis. In spite of advice he continued to play football and two years later died suddenly on the football field. There was no necropsy.

Case 3. The third child of Case 1 was 20 years of age in 1956. She had been advised not to play games at school because of her heart. When 14 she was seen by E.W.J. who found a systolic murmur in the pulmonary area, a striking triple rhythm at the apex that was hard to analyse, a blood pressure of 110/70, a large heart with a "mitral shape," a prominent pulmonary arc on X-ray, and left ventricular preponderance in the cardiogram. The signs in the brother who had just died were said to have been very similar. There was a history of slight cyanosis and this was not confirmed.

She was seen by M.C. when she was 20 and did not complain of much dyspnoa but had felt faint recently when hurrying for a bus. There was a soft murmur but the most striking sign was her triple or sometimes quadruple rhythm, especially in the fourth left space. The heart was enlarged (c.t.r. 57\%, Fig. 4A) and the 


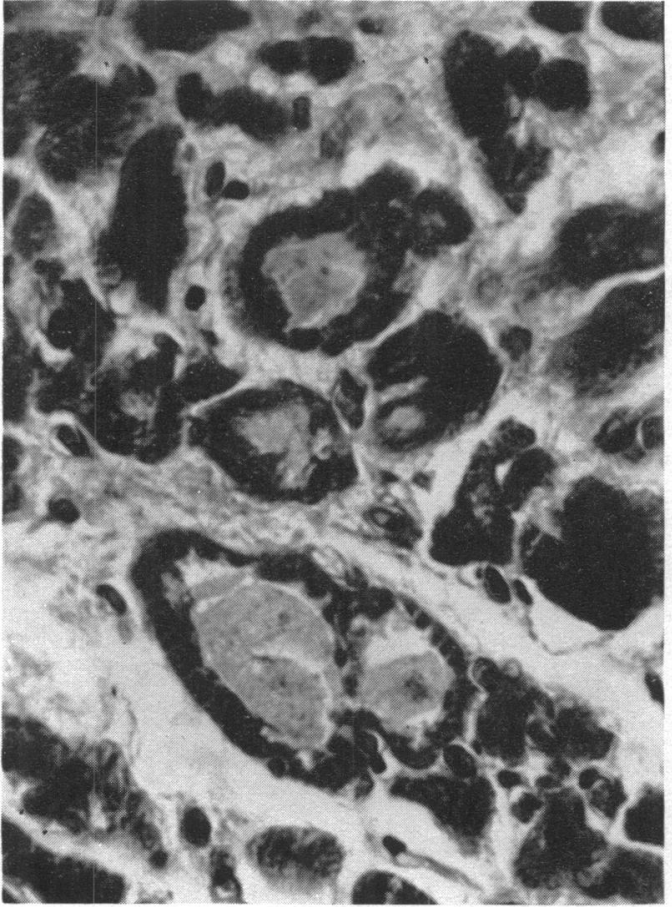

A

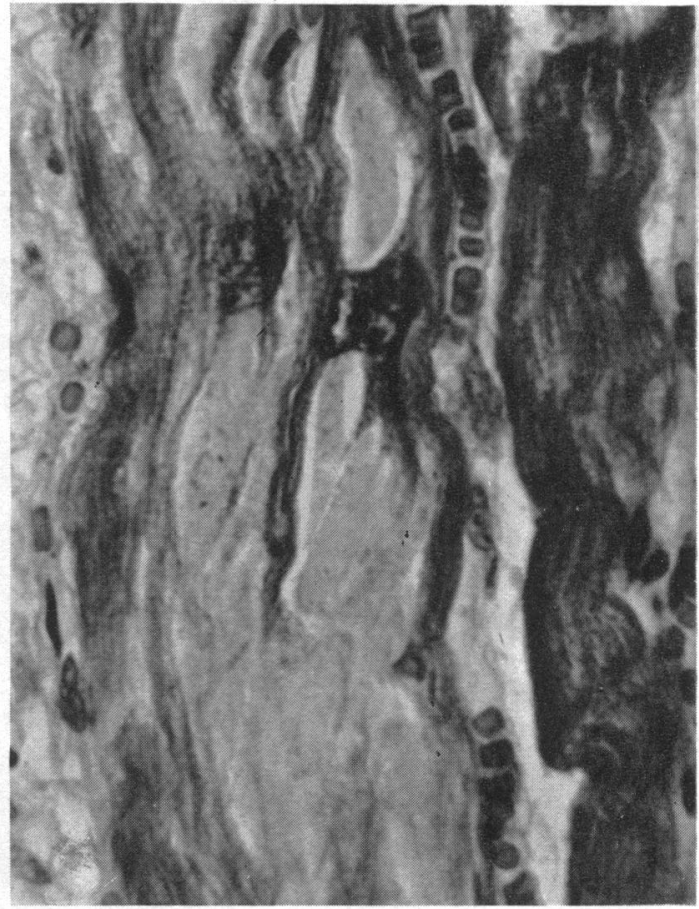

B

Fig. 3. - Myocardial fibres cut to show central mucoid material. $\times 730$. (A) Cut in transverse section. (B) Cut longitudinally. Both stained with hæmatoxylin and eosin.

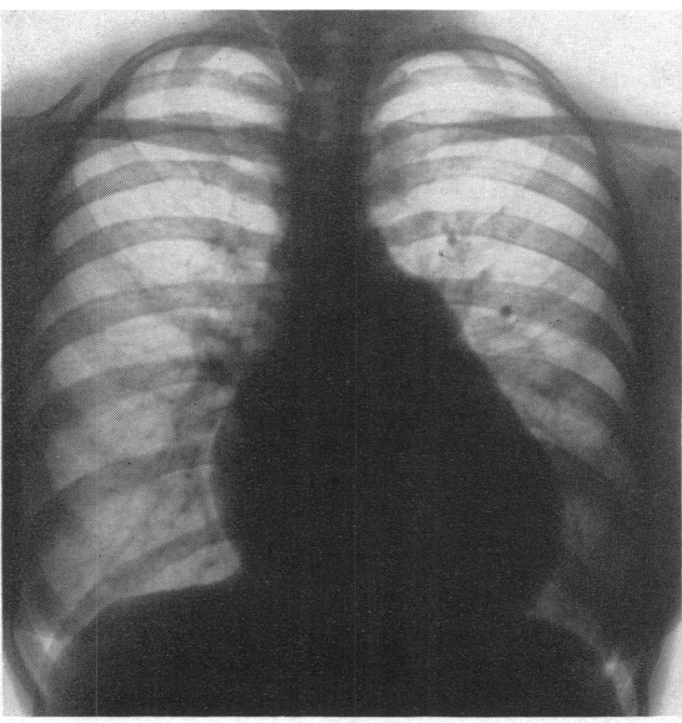

A

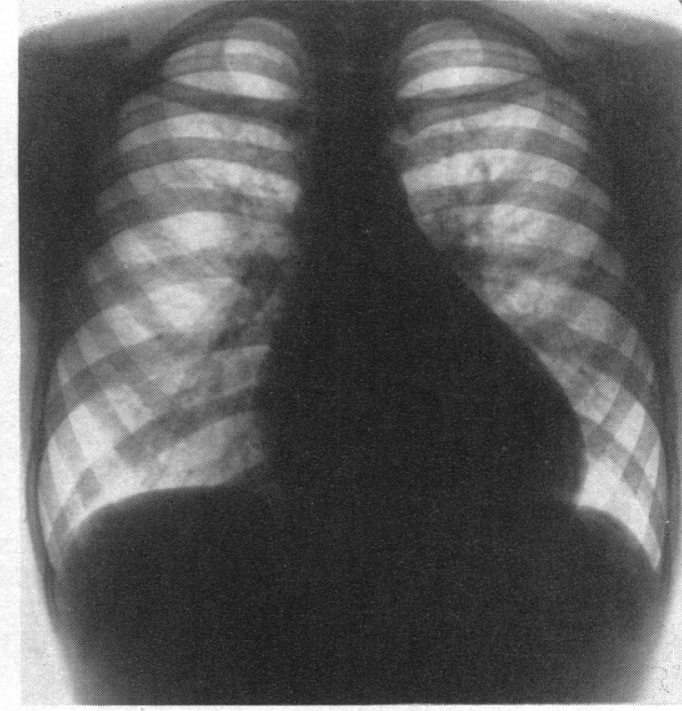

B

FIG. 4.-Teleradiogram of the enlarged heart of a sister and brother, taken in 1956 when they were 20 and 13 years of age respectively. (A) Case 3, with greater prominence of the right border and of the pulmonary $\operatorname{arc}$ (c.t.r., $57 \%: 14 \cdot 2 / 24 \cdot 8 \mathrm{~cm}$.). (B) Case 4 , with similar but less developed changes (c.t.r., $54 \%$ : $14.0 / 27 \mathrm{~cm}$.). 


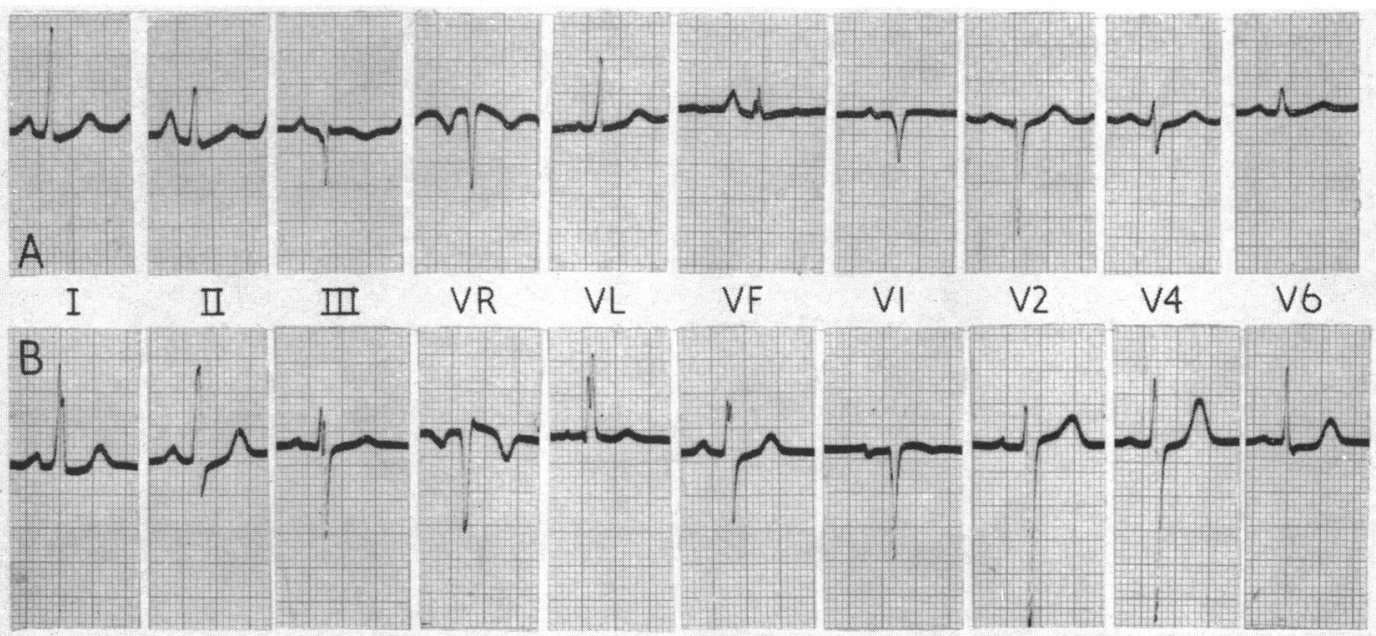

FIG. 5.-Somewhat similar electrocardiograms from the same sister and brother, taken in 1956. (A) Case 3. (B) Case 4. Both show left axis deviation and (B) shows left ventricular preponderance. In (B) and to a lesser extent in (A) there is some S-T depression in leads I and II. In both, V3 resembled V2, and V5 resembled V6; standardization $1 \mathrm{MV}=0.5 \mathrm{~cm}$. in chest leads.

rounded right border and pulmonary arc were prominent. On radioscopy there was more pulsation of the right border than of the left, and the right atrium and right ventricle seemed the main cause of the enlargement. The aorta and lung fields were not remarkable, though the density of the lung fields was at the upper limits of normal. The cardiogram had a large broad P II, left axis deviation, and some notching of the $R$ waves, but no ventricular preponderance (Fig. 5A).

Her symptoms remained much the same after her marriage and during her pregnancy. She was delivered in June 1960, when she was 24, and two weeks after she developed severe cardiac failure. After a few weeks treatment she recovered and seemed much the same as before. In September she was admitted to the Queen Elizabeth Hospital, Birmingham, under the care of J.M.B. Examination showed normal jugular venous pressure and regular rhythm. The heart was enlarged and triple rhythm of the type described above was still present, together with the systolic murmur in the pulmonary area. The blood pressure was $130 / 70 \mathrm{~mm}$. $\mathrm{Hg}$.

A phonocardiogram showed an atrial sound and first and second sounds at the apex. At the pulmonary area these sounds were present, with well-marked splitting of the second sound and a mid-systolic murmur. An additional feature was the presence of a deep $Q$ wave in lead III and a less prominent $Q$ in aVF. Hæmoglobin concentration was 12.9 g./100 ml., W.B.C. 7900 per c.mm. with a normal differential count, E.S.R. (Wintrobe) $6 \mathrm{~mm}$., and serum proteins $8.0 \mathrm{~g} . / 100 \mathrm{ml}$. with a normal electrophoretic pattern.

In spite of the possible risks, cardiac catheterization was thought advisable, especially because of the necropsy findings in her younger brother. During catheterization a variety of arrhythmias including two short runs of ventricular tachycardia were encountered when the catheter tip was in contact with the ventricular wall, but these stopped as soon as the pulmonary trunk was entered. Resting pressures were: right atrium $8 \mathrm{~mm}$. $\mathrm{Hg}$ mean, right ventricle $30 / 4 \mathrm{~mm}$., and pulmonary artery $28 / 10$ (14 mean) $\mathrm{mm}$. On exercise, R.V. 50/5 mm. and P.A. 50/28 (32 mean) mm. Satisfactory pulmonary wedge pressures were not obtained. Cardiac output at rest was 4.61 ./min. (C.I. 3.2) with oxygen uptake of $157 \mathrm{ml}$./min./sq. $\mathrm{m}$. and on exercise $6 \cdot 21 . / \mathrm{min}$. (C.I. 4.3) with an oxygen uptake of $371 \mathrm{ml} . / \mathrm{min} . / \mathrm{sq} . \mathrm{m}$. (mildly impaired response). Brachial artery oxygen saturation was 99 per cent at rest and on exercise; serial sampling did not reveal any shunt.

There was no evidence of any structural congenital disease and she was thought to have familial cardiomyopathy. She was discharged feeling well and was advised to take quinidine, $300 \mathrm{mg}$. b.i.d., to try and prevent serious arrhythmias. Her daughter, aged 3 months, appeared to be normal.

Case 4. The fourth and youngest child of Case 1, was found to have a murmur in 1950 when his brother died. He could lead a normal life and play football as a back but was more breathless running than other boys. He was seen by M.C. in 1956, when 13 years old.

The heart was enlarged (Fig. 4B; c.t.r. $54 \% ; 14.6 / 27 \mathrm{~cm}$.). The right border was rounded but this and the pulmonary arc were less prominent than in the case of his sister. There was a systolic murmur, loudest in the pulmonary area and rather squeaky towards the apex. The second sound was split in the pulmonary area and lower down the left sternal border there were sometimes four heart sounds, though this was not as 

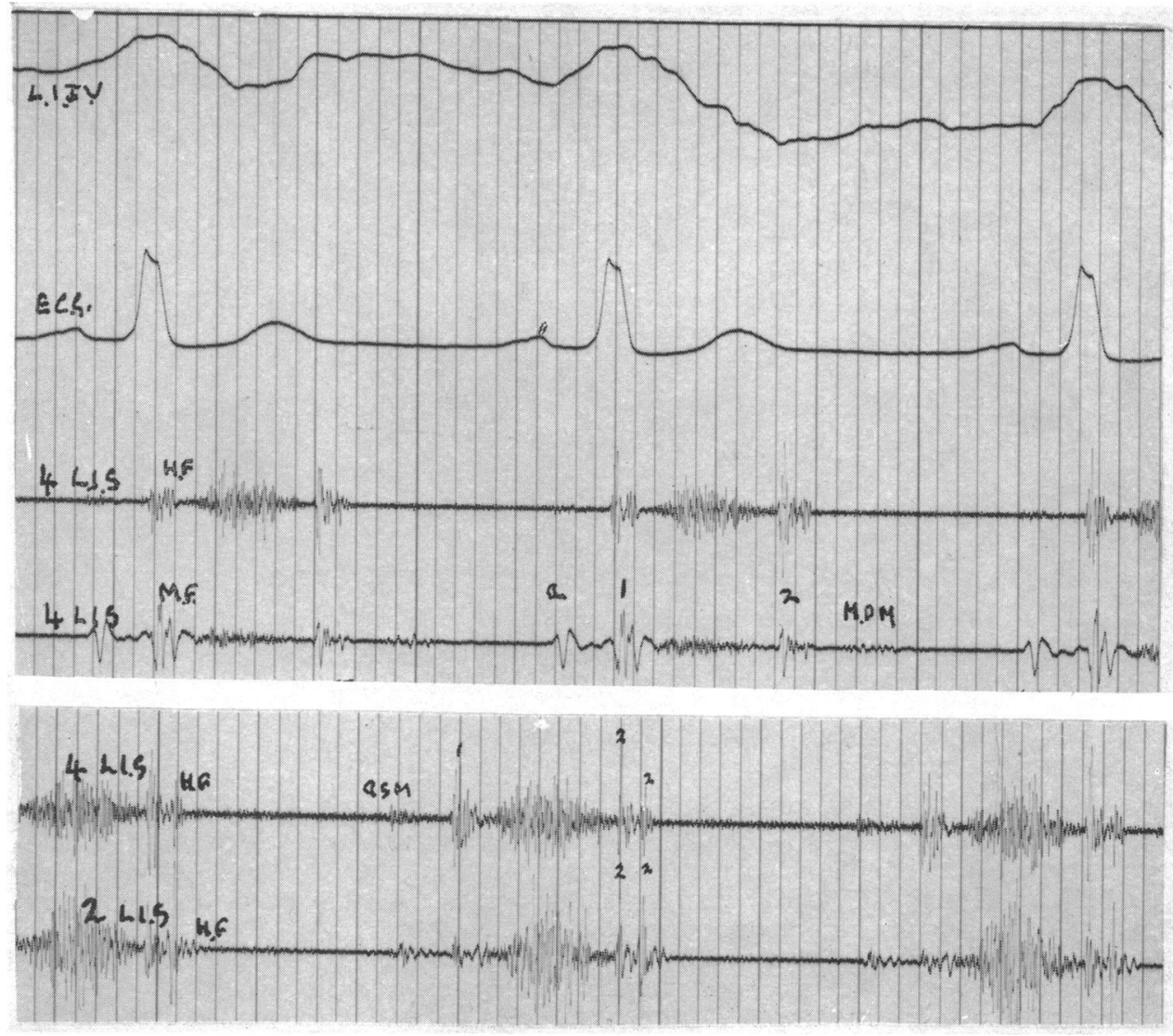

Fig. 6.-Phonocardiogram from Case 4. Above: tracing of the left internal jugular venous pulse and of lead II of the electrocardiogram. The high frequency record shows the systolic murmur and the splitting of the second sound best: the medium frequency record shows the atrial sound and the diastolic murmur better. Below: two more high frequency records showing the splitting of the second sound more clearly. It seems likely that the four sounds heard were the atrial sound, the first sound, and the well-split second sound, though the fourth sound heard could have been the short mid-diastolic murmur.

striking as the triple rhythm. Phonocardiograms showed that the first heart sound was normally registered in all areas and that the aortic and pulmonary components of the second sound were separated by $0.045 \mathrm{sec}$., the pulmonary being about twice the amplitude of the aortic. The atrial sound was accentuated and the third heart sound was recorded at the apex. The systolic murmur, rhomboid in shape, started well after the first sound, was maximal in mid-systole, and ended before A2. There was a short low-amplitude, middiastolic murmur at the apex (Fig. 6). It seems likely that the four sounds heard were the atrial sound, the first sound, and the well-split second sound.

The systolic murmur was rather louder than his sister's and better heard towards the apex; no thrill was felt. The blood pressure was $120 / 65$. On radioscopy there was the same striking pulsation of the right border and the enlargement seemed mainly the right atrium and right ventricle but partly the left ventricle as well: the aorta and the lung fields seemed normal. The cardiogram (Fig. 5B) showed less change in the $\mathbf{P}$ waves, but more notching with primary and secondary $R$ waves in VL and left ventricular preponderance ( $\mathrm{S}$ in $\mathrm{V} 1,28+\mathrm{R}$ in $\mathrm{V} 6,18)$.

Four years later, when he was 17 , he died suddenly in the street. So far as is known, he had been in his usual health until this time.

Necropsy. The heart was large and weighed 690 g., mainly owing to a hypertrophied left ventricle. There was also a persistent ductus arteriosus with coarctation of the aorta just beyond this. The aortic arch was widened. No disease of the valves or of the coronary arteries was observed. The pericardium contained 
about $50 \mathrm{ml}$. of brownish fluid and the lungs showed acute pulmonary œdema. Unfortunately, no histological examination of the heart muscle was made.

The last blood pressure reading that had been recorded before his death was $120 / 65$, so in the ordinary way this would show that his coarctation was not very severe. In this case, however, the communication between the aorta and the pulmonary artery may have tended to lower the pressure on the systemic side, as it certainly does when there is also a ventricular septal defect (Newcombe, 1960).

Case 5. A first cousin of Cases 2,3, and 4 died suddenly when he was 42: he was a son of their mother's brother. He was obese and began to suffer from anginal pain in 1951, at the age of 37 . No comment was made about any abnormality of the heart sounds and there were no murmurs. He had radiological signs of left ventricular enlargement. The blood pressure was $200 / 120$ but there was no evidence of coarctation of the aorta. Standard lead electrocardiograms were not grossly abnormal. There was no evidence of hiatus hernia or of duodenal ulcer. The anginal pain became worse during the next four years and he died suddenly in 1956 at the age of 42 years. There was no necropsy. This seems to have been quite a different condition but Whitfield (1961) has emphasized the occurrence of anginal pain in three of his patients with cardiomyopathy, with normal coronary arteries in the one who came to necropsy.

Fourth Generation. There are at present 7 children of this generation, including one daughter of Case 3, now aged 2 years. Their ages range from 2 to 16 years and so far there is no evidence of heart disease in any of them.

\section{Discussion}

Since Evans' (1949) original account of familial cardiomegaly, many others have been addedat first slowly but in recent years more frequently and for families where many more members were affected. In 1956 we still used the term familial cardiomegaly, but since Brigden (1957) wrote of familial cardiomyopathy, this term has generally been used. We think it is a better and more accurate name, although the heart is generally large and sometimes very large-1300 g. in a man aged 19 (Hayes et al., 1959); $1134 \mathrm{~g}$. in Case 1 of Evans (1949); and $1050 \mathrm{~g}$. in Case 3 of Campbell and Turner-Warwick (1956). As a result of the recent accounts we now know a good deal about the general picture and about its inheritance, though it is still uncertain if there are two or more clinical entities or if they are all varieties of the same condition.

Evans (1949) described 7 affected subjects, several of them with very large hearts and conduction defects: five of them were in two families-(1) a mother and son and (2) a mother and two sons. No cases of this type seem to have been reported previously, though a man and his sister, both with heart failure and complete heart block, and perhaps a younger brother were described in the Case Records of the Massachusetts General Hospital (1942); and Addarii et al. (1946) mentioned a girl of 14 who died with heart block and heart failure and her mother who had died young with a syncopal syndrome.

Davies (1952) described a somewhat similar condition in 4 sisters and 1 brother, the two patients with necropsy having also aortic stenosis : their parents and 6 of the 7 children in the third generation were normal, but the seventh, a son of one of the sisters, was affected. Gaunt and Lecutier (1956)

reported three cases - a woman and her brother and her daughter-that were very similar to those of Evans. Campbell and Turner-Warwick (1956) reported two families in both of which a mother and her only son were both affected: in one, 12 of the 13 sibs of the mother had died young, 8 of them from heart disease; and in the other there were several relatives who had unusual forms of heart disease, but only the first four who were seen have been included in Table I. Though Paulley et al. (1956) attributed their cases to toxoplasmosis, this was doubtful: in one family the mother and three of her six children were affected, and in the second two brothers were affected, their two sisters and their parents being normal.

Brigden (1957) gave a clear summary of these with a useful reproduction of most of the family trees, and added two families of his own: in one, a brother and sister and their mother were affected; and in the other, 4 or perhaps 5 brothers. Soulié et al. (1957) described a brother and sister and their uncle: in the brother the necropsy showed the same changes of hypertrophy and vacuolation of the muscle fibres with some fibrosis. 
In 1958-60, Teare and Goodwin and their colleagues described a type of obstructive cardiomyopathy that seemed somewhat different (Teare, 1958; Goodwin et al., 1960) as the muscle was so hypertrophied that it produced valvular obstruction, most often aortic stenosis, though in several of the 9 affected members with a familial incidence, the obstruction was in the outflow tract of the right ventricle (Hollman et al., 1960). Brent et al. (1960) also described two families where 12 members had hypertrophied hearts and subaortic stenosis with a tendency to sudden death.

Since then, several larger families have been reported. Whitfield (1961) described a large family where 16 members ( 3 men and 13 women) in four generations were affected with a cardiomyopathy. During childhood they were generally without symptoms, but later developed dyspnœa and three had cardiac pain. Most had some enlargement of the heart and a systolic murmur, most often basal. Three died suddenly aged 17,36 , and 40 years, and three with congestive heart failure, aged 27,54 , and 57 respectively. There were only two necropsies: one done by the coroner described fatty and myocardial degeneration, and in the other where the heart weighed $335 \mathrm{~g}$., the pale firm muscle showed widespread hypertrophy of myofibrils and patchy atrophy and fibrosis.

Paré et al. (1961) have described a remarkable French Canadian family descended from the marriage of two cousins once removed in the 17th century. In five generations, there were 20 members with cardiomyopathy and another 10 of the 77 members had probably died with this. In all, 8 had died suddenly, and there were 3 necropsies out of the 5 who died during the period of study. Dyspnœa and syncopal attack were the main presenting symptoms and the average age at death of the affected members was only 34 years. Battersby and Glenner (1961) described 5 sibs with cardiomyopathy and in the two with necropsies the changes in the heart were almost identical.

Most of this was written before seeing the paper by Barry and Hall (1962) who described 14 affected subjects in five generations. Thus, the last two or three years have added several families with large numbers of affected members. This suggests that more examples should generally be found if looked for. In our family, however, careful inquiries failed to reveal any others who were affected, and this might be expected if the condition in our Case 1 has arisen as a mutation.

Our family is unusual also in having a cardiomyopathy associated with congenital malformations of the heart-a persistent ductus and coarctation of the aorta-in the same patient (Case 4). This provides slight additional evidence that the cardiomyopathy also had a congenital basis, though it is clear that in most of the reported families symptoms do not generally develop for many years.

\section{General Picture and Classification}

Perhaps the most striking symptom is the great liability to sudden death, most often between 20 and 40 years of age. Other subjects may die between 40 and 50 with congestive heart failure. Symptoms are often slight or even absent till near the end, though there may be some dyspnœa or palpitation. Conduction defects and other arrhythmias are often found in the electrocardiogram. The heart is enlarged, often greatly so, and may weigh over $1000 \mathrm{~g}$. though weights of about 550 to $650 \mathrm{~g}$. are more usual. There is sometimes a basal systolic murmur, so perhaps obstructive aortic stenosis is present more often than has been recognized. As far as symptoms are concerned, the subjects might all belong to one group.

In the present state of knowledge it seems reasonable to divide the families into two groups-(1) those where the great hypertrophy of the muscle, especially of the left ventricle and septum, produces obstructive stenosis below the aortic valve or in the right ventricle and its outflow tract; and (2) those where this does not happen. The necropsy findings of Paré et al. (1961) in two of their subjects of enough muscular hypertrophy to cause subaortic stenosis suggest that the two groups may not be as distinct as has been thought. Barry and Hall (1962) sub-divided the latter group into (2) those with fibrosis and (3) those without fibrosis. In most of the families reported fibrosis has been found, though the degree of it has varied, and the fact that it was not found or mentioned in some of the cases hardly seems to us a valid reason for separation.

The histological findings described in most of the necropsy reports are similar though by no means 
identical. Hypertrophy of the muscle fibres is constant with varying degrees of fibrosis. The degree of vacuolation of other muscle fibres described is more variable, but there is little or no cellular infiltration of the muscle or other signs of inflammatory change.

The significance of the mucoid material deposited within muscle fibres that was found at the necropsy by Missen in our Case 1 is not clear. Recently, Missen has found this again in a more extreme form at the necropsy on a boy of 16 with a cardiomyopathy whose sister also had died young, probably with the same condition (to be published). Lesser degrees of such mucoid deposits are by no means confined to cardiomyopathy for Spencer (1950) found it in the hearts of 30 patients who died from various conditions; 26 of the 30 were over 50 years of age and several of them had suffered from renal failure from various causes.

Neither the symptoms, nor the histological changes appear to give adequate grounds for differentiating familial cardiomyopathy into several groups. It seems likely that we shall not be certain whether the condition is a single entity or several entities until more is known about the metabolic changes in the heart muscle. Probably the disorder is another example of Garrod's inborn errors of metabolism, where some chemical defect causes less effective contraction of the muscle fibres: the hypertrophy of the fibres may well be an attempt to overcome this weakness.

\section{Mode of Inheritance}

It seems worth considering what conclusions can be drawn about the mode of inheritance of familial cardiomyopathy. Campbell and Turner-Warwick (1956) concluded that it was probably due to a Mendelian dominant gene, though the affected members in the families that were reported earlier were not many in number and were more often sibs. Brigden (1957) pointed out that where members of two generations were affected, the condition was nearly always inherited through a mother who was herself affected. This was still true of the larger family reported by Whitfield (1961), but not of the families reported subsequently. A young patient is more likely to attend hospital with his mother so the presence of cardiomyopathy may be detected more readily in her than in the father, and Brigden (personal communication) thinks there is some evidence of earlier deaths in the men than in the women so that children may be less likely.

TABLE I

Sex of Subjects with Familial Cardiomyopathy and their Normal Sibs

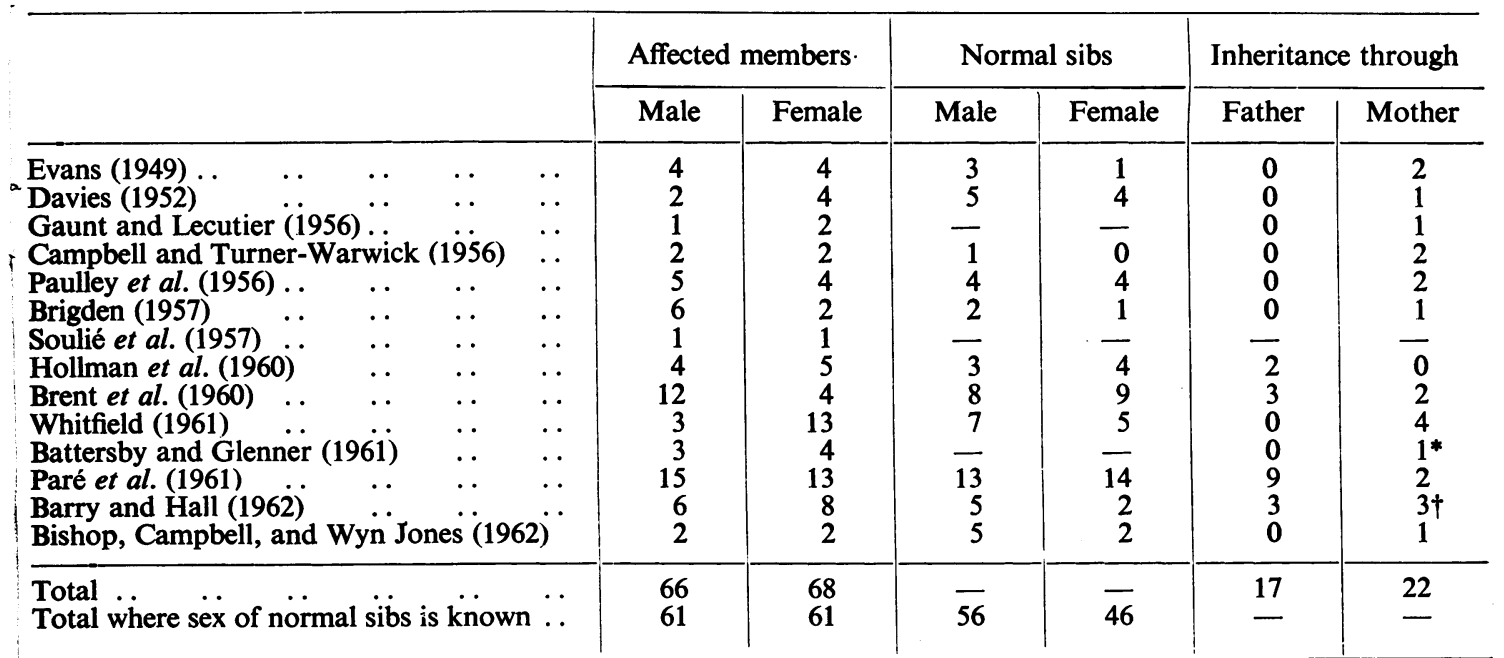

* Indicates apparent inheritance through a healthy mother.

† Indicates apparent inheritance through one, or perhaps two, healthy mothers. 
Brent et al. (1960) thought that in their family the condition was inherited as a Mendelian dominant gene. Paré et al. (1961) found that the cardiomyopathy was equally distributed in the two sexes and occurred in half the children of affected parents, so they considered it was inherited as an autosomal dominant character. Barry and Hall (1962) thought it was inherited by a dominant gene with incomplete penetrance, because there were two examples of inheritance through mothers who were apparently healthy (Cases B1 and C9): the former was thought to have familial cardiomyopathy but the necropsy suggested some form of myocarditis, and the latter was found to be normal on examination. This was also the case in the family of Battersby and Glenner (1961) as the relationship between the sibs and their cousins who were probably affected was through a healthy mother. This led the authors to suspect a recessive mode of inheritance but the general evidence is all against this unless there are different modes of inheritance: this is possible but at present the evidence is against it.

The sex of the affected members, the number of normal subjects in each sibship, and the sex of the parent through whom the condition was inherited in the families that have been reported are set out in the Table. The figures are not exact because we have decided arbitrarily whether members described as probably affected should be included as affected or omitted. It will be seen that (1) men and women were equally affected; (2) approximately half the members of the sibships were affected; and (3) the condition was inherited nearly as often through men as through women. All these findings support the view that familial cardiomyopathy is inherited as an autosomal dominant Mendelian character.

Cardiomyopathies with Diseases of the Nervous System. More is known about the inheritance of several diseases of the nervous and muscular systems; and as some of these are liable to have an associated cardiomyopathy, it is interesting to see how these fit in with the hereditary factor. Evans and Wright (1942) found 45 cases with myocardial changes in 29 families with Friedreich's disease, where the type that starts in early childhood is generally inherited as a recessive character and the type that starts in early adult life as a dominant character. They found 2 sibs in 5 families, 3 sibs in 2 families, and 4 sibs in 2 families, and only 1 uncle and nephew, which would fit in with recessive inheritance: 15 of their 22 patients with abnormal electrocardiograms had affected relatives but only 4 of their 16 with normal cardiograms.

Several authors have mentioned rather late involvement of the heart in myotonia atrophica which often has a Mendelian recessive inheritance. Evans (1944) and Spillane (1951), however, found only 2 affected brothers among their 29 cases. Spillane failed to find any similar cardiac changes in unaffected members of the families, so presumably the heart condition is inherited in the same way as the nervous disease.

Manning and Cropp (1958) found signs of heart involvement in about 70 per cent of the juvenile type of pseudo-hypertrophic muscular dystrophy which has a rather variable type of sex-linked recessive inheritance; but rarely, if ever, in the facio-scapulo-humeral group which has an autosomal dominant inheritance. They did not discuss the familial incidence. In most of these neurological conditions, the cardiomyopathy is found only in some of the members of the family with the neurological disease. Kiloh and Niven (1951), however, reporting a man with pseudo-hypertrophic muscular dystrophy and cardiomegaly, found one of his brothers without the muscular dystrophy had died with cardiomegaly at the age of 42 , while another brother had only the muscular dystrophy.

\section{SUMMARY}

A mother and three of her four children with a cardiomyopathy have been described: one of them had also associated congenital heart disease. The reported families with cardiomyopathy have been reviewed.

The symptoms, with the grave liability to sudden death in early adult life, and the histological changes are not enough at present to decide if there are one or more entities making up the group. Even the types with obstructive cardiomyopathy simulating aortic stenosis may be a variety of the 
same condition. Probably this will not be settled till more is known about the metabolic abnormality of the heart muscle.

Familial cardiomyopathy is generally inherited as an autosomal dominant Mendelian character.

We should like to thank Dr. T. J. A. Lloyd, Dr. L. Wise, and Dr. G. K. Missen for pathological details of Case 1; and Dr. L. Wise and Dr. R. S. Brock for help in following up the other members of the family.

\section{REFERENCES}

Addarii, F., Martini, L., Mahaim, I., and Winston, M. (1946). Nouvelles recherches sur le bloc bilatéral manqué. Cardiologia (Basel), 11, 36.

Barry, M., and Hall, M. (1962). Familial cardiomyopathy. Brit. Heart J., 24, 613.

Battersby, E. J., and Glenner, G. G. (1961). Familial cardiomyopathy. Amer. J. Med., 30, 382.

Brent, L. B., Aburano, A., Fisher, D. L., Moran, T. J., Myers, J. D., and Taylor, W. J. (1960). Familial muscular subaortic stenosis. Circulation, 21, 167.

Brigden, W. (1957). Uncommon myocardial diseases - the non-coronary cardiomyopathies. Lancet, 2, 1179 and 1243.

Campbell, M., and Turner-Warwick, M. (1956). Two more families with cardiomegaly. Brit. Heart J., $18,393$.

Case Records of the Massachusetts General Hospital (1942). New Engl. J. Med., 226, 158.

Davies, L. G. (1952). A familial heart disease. Brit. Heart J., 14, 206.

Evans, W. (1944). The heart in myotonia atrophica. Brit. Heart J., 6, 41. (1949). Familial cardiomegaly. Brit. Heart J., 11, 68.

- , and Wright, G. (1942). The electrocardiogram in Friedreich disease. Brit. Heart J., 4, 91.

Gaunt, R. T., and Lecutier, M. A. (1956). Familial cardiomegaly. Brit. Heart J., 18, 251.

Goodwin, J. F., Hollman, A., Cleland, W. P., and Teare, D. (1960). Obstructive cardiomyopathy simulating aortic stenosis. Brit. Heart J., 22, 403.

Hayes, W. L., Dimond, E. G., and Crockett, J. E. (1959). Idiopathic cardiomegaly with extreme cardiac enlargement. Amer. J. Cardiol., 4, 528.

Hollman, A., Goodwin, J. F., Teare, D., and Renwick, J. W. (1960). A family with obstructive cardiomyopathy. Brit. Heart J., 22, 449.

Kiloh, L. G., and Nevin, S. (1951). Pseudohypertrophic muscular dystrophy with cardiomegaly. Proc. roy. Soc. Med., 44, 694.

Manning, G. W., and Cropp, G. J. (1958). The electrocardiogram in progressive muscular dystrophy. Brit. Heart J., $20,416$.

Newcombe, C. P. (1960). The assessment of coarctation of the aorta with associated ventricular septal defect. Brit. Heart J., 22, 588.

Paré, J. A. P., Fraser, R. G., Pirozynski, W. J., Shanks, J. A., and Stubington, D. (1961). Hereditary cardiovascular dysplasia. Amer. J. Med., 31, 37.

Paulley, J. W., Jones, R., Green, W. P. D., and Kane, E. P. (1956). Myocardial toxoplasmosis. Brit. Heart J., $18,55$.

Soulié, P., Mattéo, J. di, Abaza, A., Nouaille, J., and Thibert, M. (1957). Cardiomégalie familliale. Arch. Mal. Cour, 50, 22.

Spencer, H. (1950). Mucoid degeneration of the heart muscle. J. Path. Bact., 62, 653.

Spillane, J. D. (1951). The heart in myotonia atrophica. Brit. Heart J., 13, 343.

Teare, D. (1958). Asymmetrical hypertrophy of the heart in young adults. Brit. Heart J., $20,1$.

Whitfield, A. G. W. (1961). Familial cardiomyopathy. Quart. J. Med., 30, 119. 